\title{
Eulerian Simulations of Bubbling Behavior in a Gas-Solid Fluidized Bed: Role of Solid Frictional Viscosity
}

\author{
Brajesh K. Singh, Shantanu Roy, Vivek V. Buwa* \\ Department of Chemical Engineering, Indian Institute of Technology Delhi, New Delhi \\ 110016, India \\ (* corresponding author: vvbuwa@iitd.ac.in)
}

\section{Supplementary information}

Table S1. Kinetic Theory of Granular Flow (KTGF) closure models

- Solid pressure Lun et al. ${ }^{1}$

$$
p_{s}=\alpha_{s} \rho_{s} \Theta_{s}+2 \rho_{s}\left(1+e_{s s}\right) \alpha_{s}^{2} g_{0, s s} \Theta_{s}
$$

- Diffusional co-efficient of granular temperature Gidaspow ${ }^{2}$

$$
k_{\Theta s}=\frac{150 \rho_{s} d_{s} \sqrt{\Theta_{s} \pi}}{384\left(1+e_{s s}\right) g_{0, s s}}\left[1+\frac{6}{5} g_{0, s s} \alpha_{s}\left(1+e_{s s}\right)\right]^{2}+2 \rho_{s} d_{s} \alpha_{s}^{2}\left(1+e_{s s}\right) g_{0, s s} \sqrt{\frac{\Theta_{s}}{\pi}}
$$

- Collisional energy dissipation Lun et al. ${ }^{1}$

$$
\gamma_{\Theta_{s}}=\frac{12\left(1-e_{s s}^{2}\right) g_{0, s s}}{d_{s} \sqrt{\pi}} \rho_{s} \alpha_{s}^{2} \Theta_{s}^{3 / 2}
$$

- Radial distribution function by Syamlal et al. ${ }^{3}$

$$
g_{o, s s}=\frac{1}{1-\alpha_{s}}+\frac{3 \alpha_{s}}{\left(1-\alpha_{s}\right)^{2}}
$$

- Solid bulk viscosity (Lun et al. ${ }^{1}$ )

$$
\lambda_{s}=\frac{4}{3} \alpha_{s}^{2} \rho_{s} d_{s} g_{0, s s}\left(1+e_{s s}\right)\left(\frac{\Theta_{s}}{\pi}\right)^{1 / 2}
$$




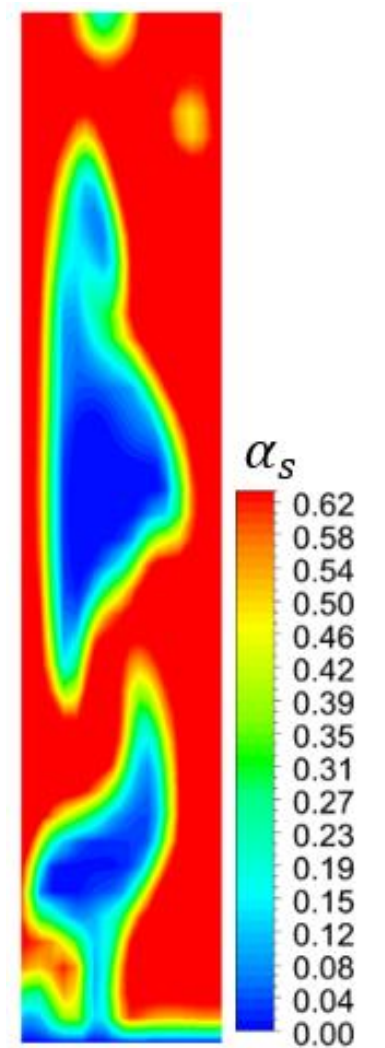

(a)

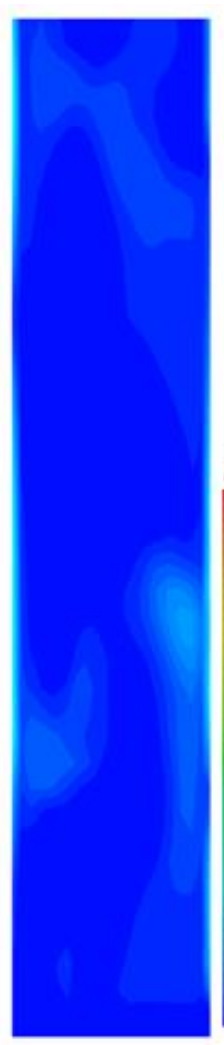

(b)

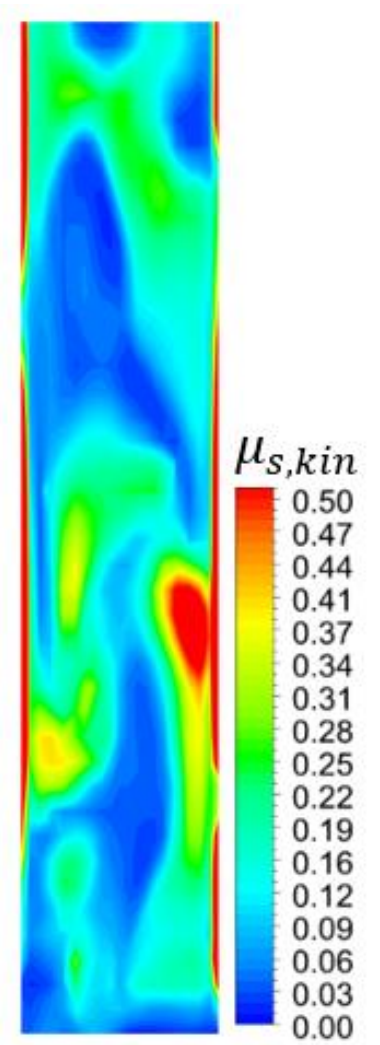

(c)

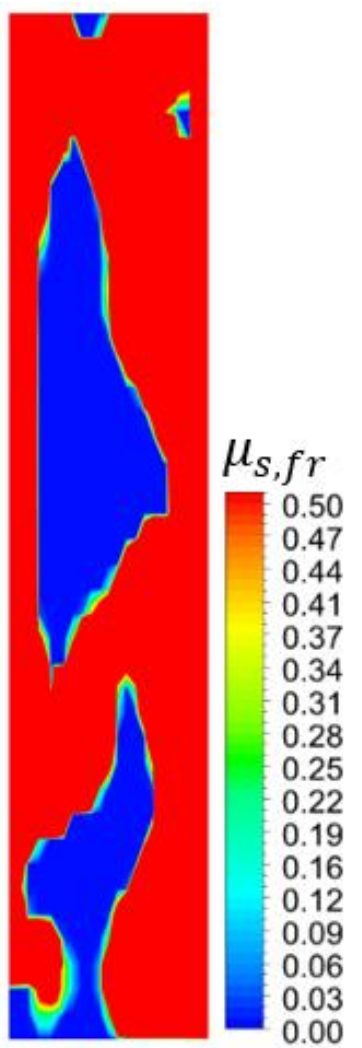

(d)

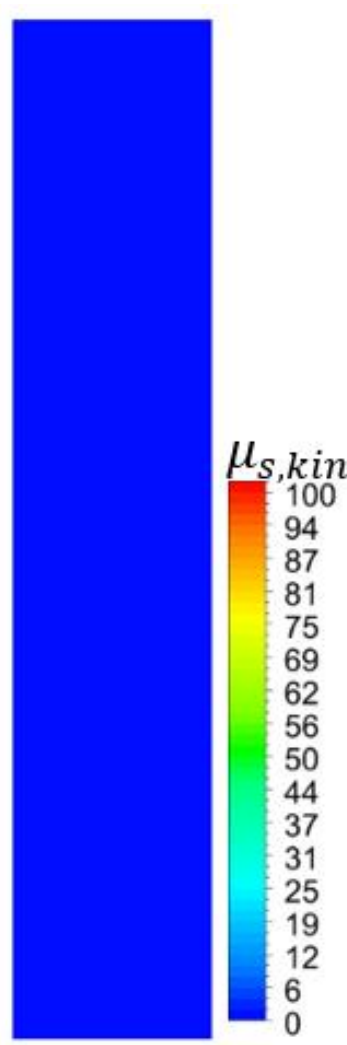

(e)

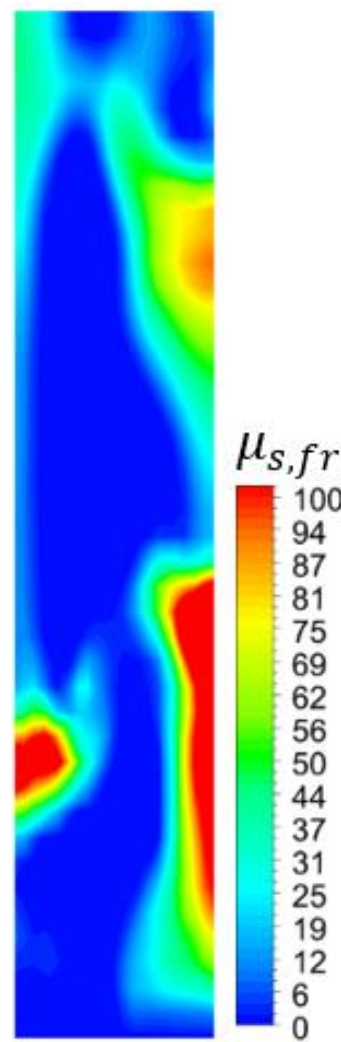

(f)

Figure S1. Instantaneous distributions of (a) $\alpha_{s}$, (b) $\mu_{s, c o l}$, (c) $\mu_{s, k i n}$, (d) $\mu_{s, f r}$ predicted using frictional viscosity model with Johnson-Jackson based frictional pressure (JJ- $\mu_{s, f r}$ ). In figures (e) and (f), the $\mu_{s, k i n}$ and $\mu_{s, f r}$, respectively, are shown for the scale of 0 to 100 Pa.s. (G96, U $=0.9 \mathrm{~m} / \mathrm{s}$ ). Also, note that the distributions up to the dispersed height (and not for full domain height) are shown. 


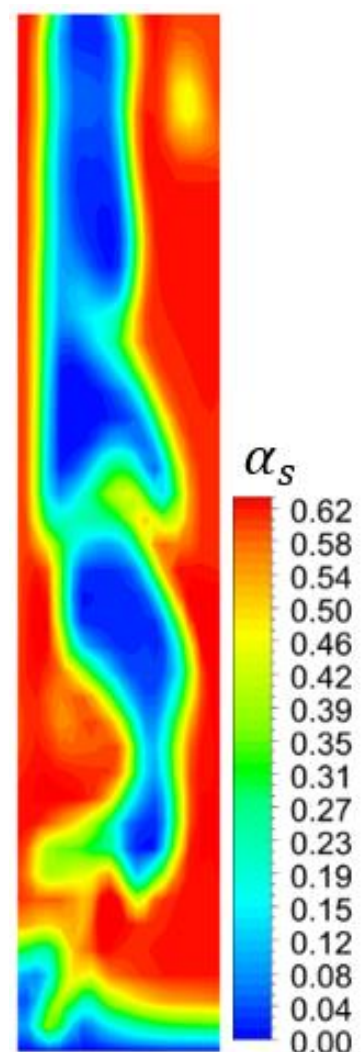

(a)

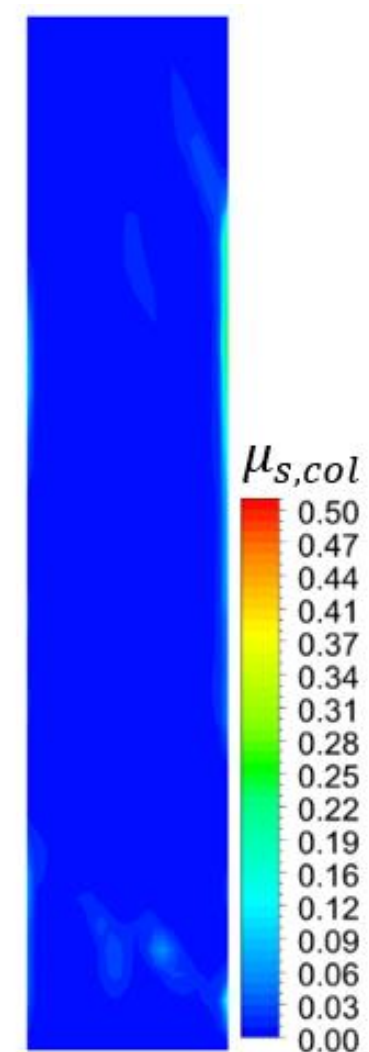

(b)

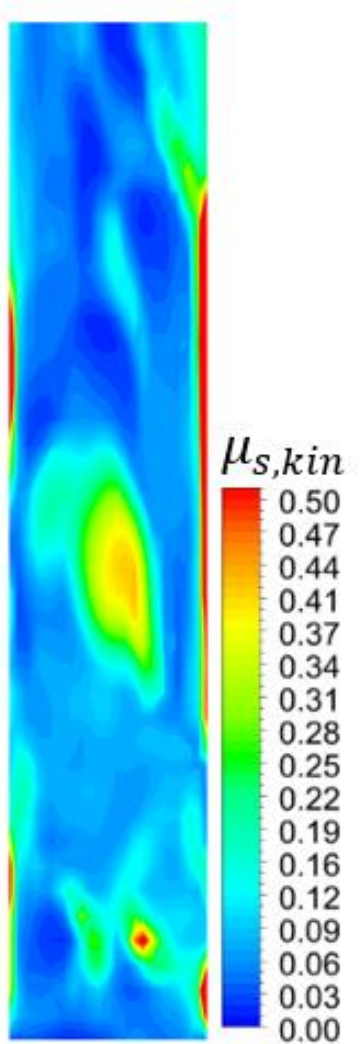

(c)

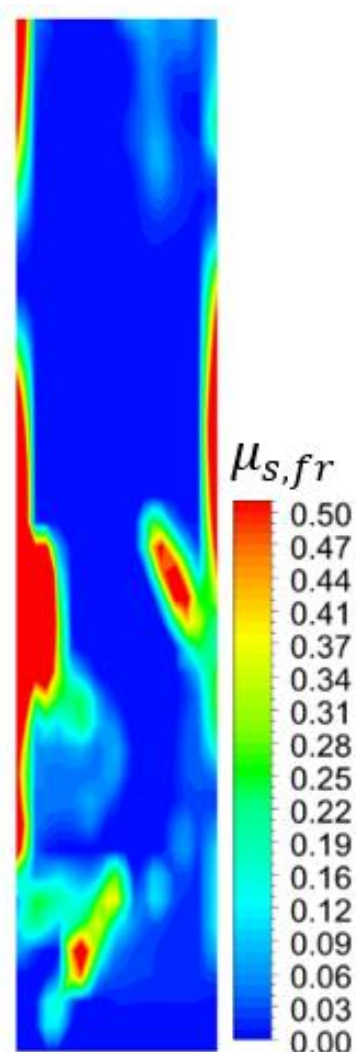

(d)

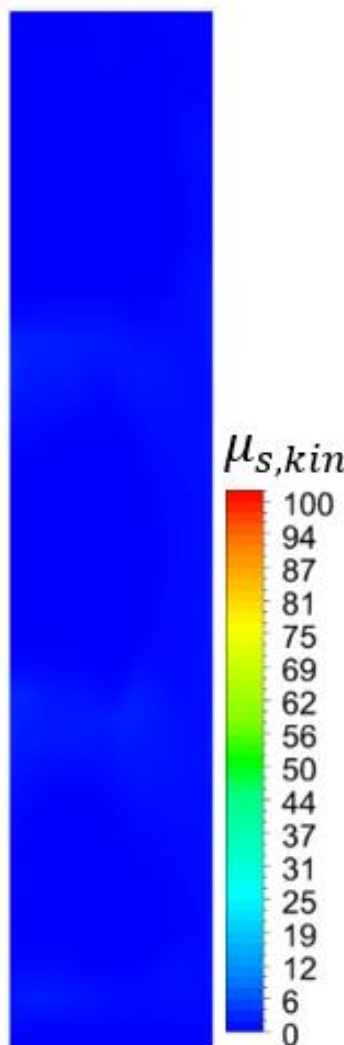

(e)

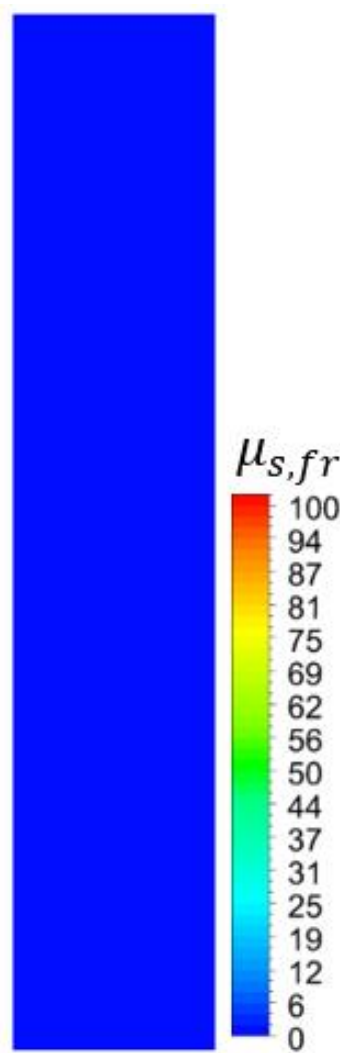

(f)

Figure S2. Instantaneous distributions of (a) $\alpha_{s}$, (b) $\mu_{s, c o l}$, (c) $\mu_{s, k i n}$, (d) $\mu_{s, f r}$ predicted using frictional viscosity model with KTGF based frictional pressure (KTGF- $\mu_{s, f r}$ ). In figures (e) and (f), the $\mu_{s, k i n}$ and $\mu_{s, f r}$, respectively, are shown for the scale of 0 to 100 Pa.s. (G96, UG $=$ $0.9 \mathrm{~m} / \mathrm{s}$ ). Also, note that the distributions up to the dispersed height (and not for full domain height) are shown. 


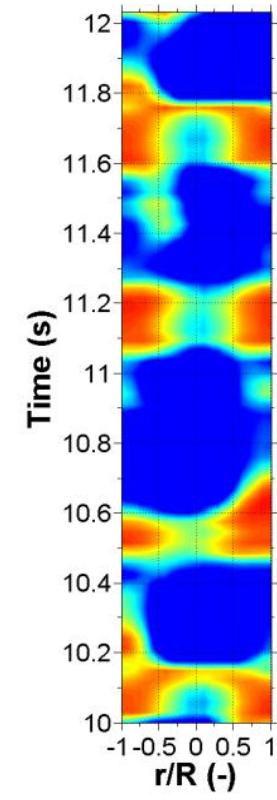

(a)

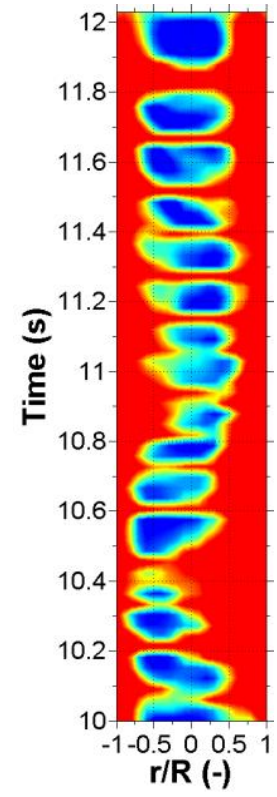

(b)

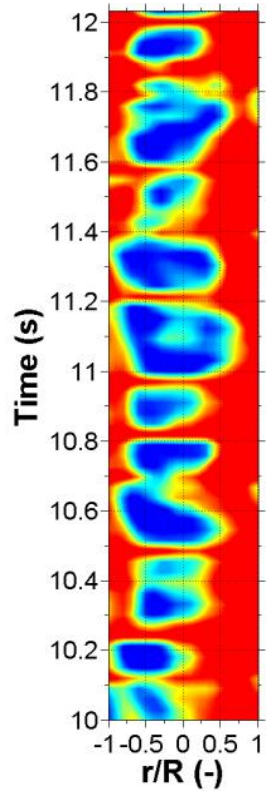

(c)

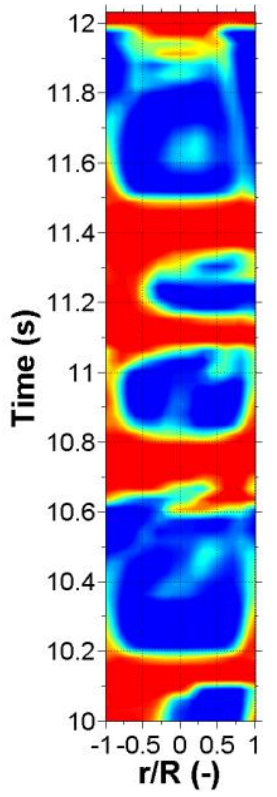

(i)

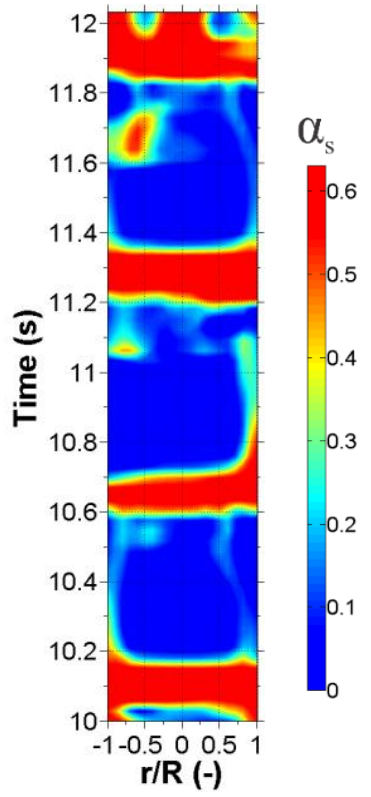

(ii)

(d)

Figure S3. Time-evolution of $\alpha_{s}$ distribution along the diameter of the bed (a) measured using the $\mathrm{ECT}^{4}$, (b) predicted without $\mu_{s, f r}$, (c) predicted with KTGF- $\mu_{s, f r}$ and (d) predicted with JJ- $\mu_{s, f r}$ models. In the case of (d), JJ- $\mu_{s, f r}$ was calculated using (i) $\alpha_{s, \min }=0.5$ and (ii) $\alpha_{s, \min }=0.55\left(\mathrm{G} 922, \mathrm{z}=24 \mathrm{~cm}, \mathrm{U}_{\mathrm{G}}=1.75 \mathrm{~m} / \mathrm{s}\right)$. 


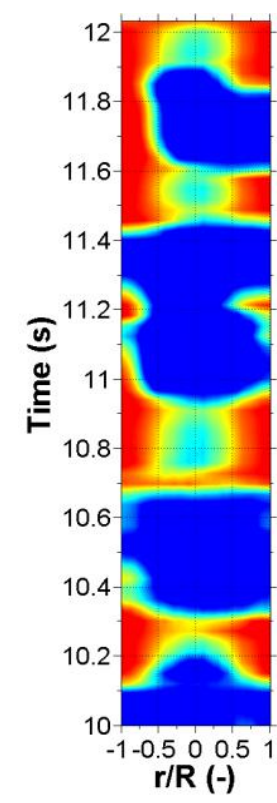

(a)

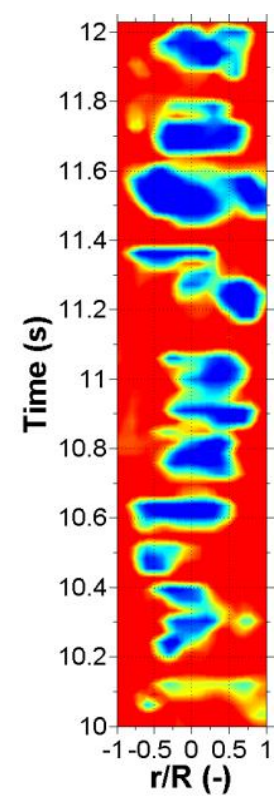

(b)

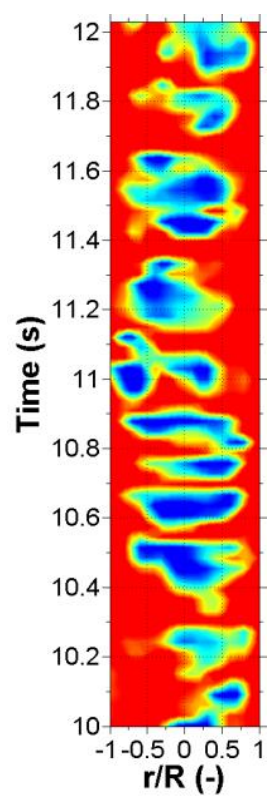

(c)

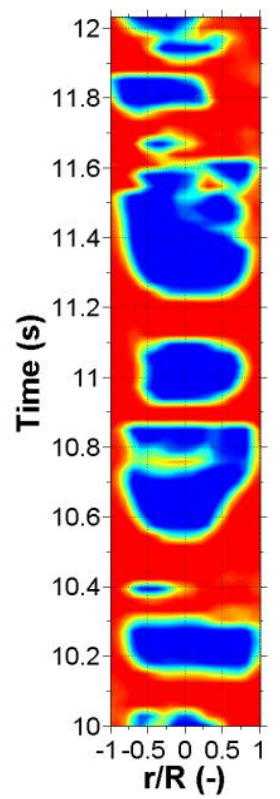

(i)

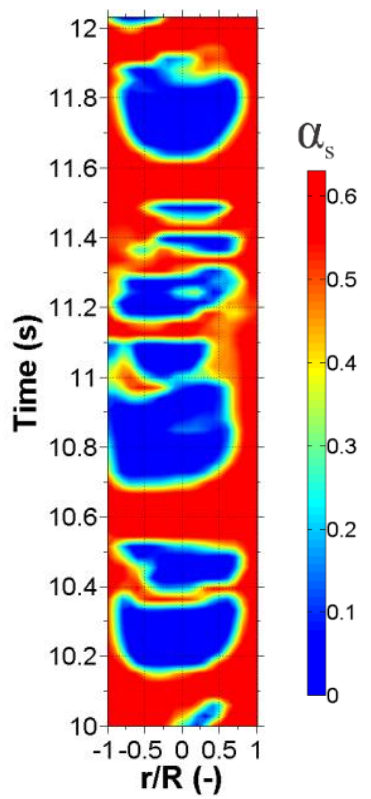

(ii)

(d)

Figure S4. Time-evolution of $\alpha_{s}$ distribution along the diameter of the bed (a) measured using the $\mathrm{ECT}^{4}$, (b) predicted without $\mu_{s, f r}$, (c) predicted with KTGF- $\mu_{s, f r}$ and (d) predicted with JJ- $\mu_{s, f r}$ models. In the case of (d), JJ- $\mu_{s, f r}$ was calculated using (i) $\alpha_{s, \min }=0.5$ and (ii) $\alpha_{s, \min }=0.55\left(\mathrm{G} 96, \mathrm{z}=24 \mathrm{~cm}, \mathrm{U}_{\mathrm{G}}=0.44 \mathrm{~m} / \mathrm{s}\right)$. 


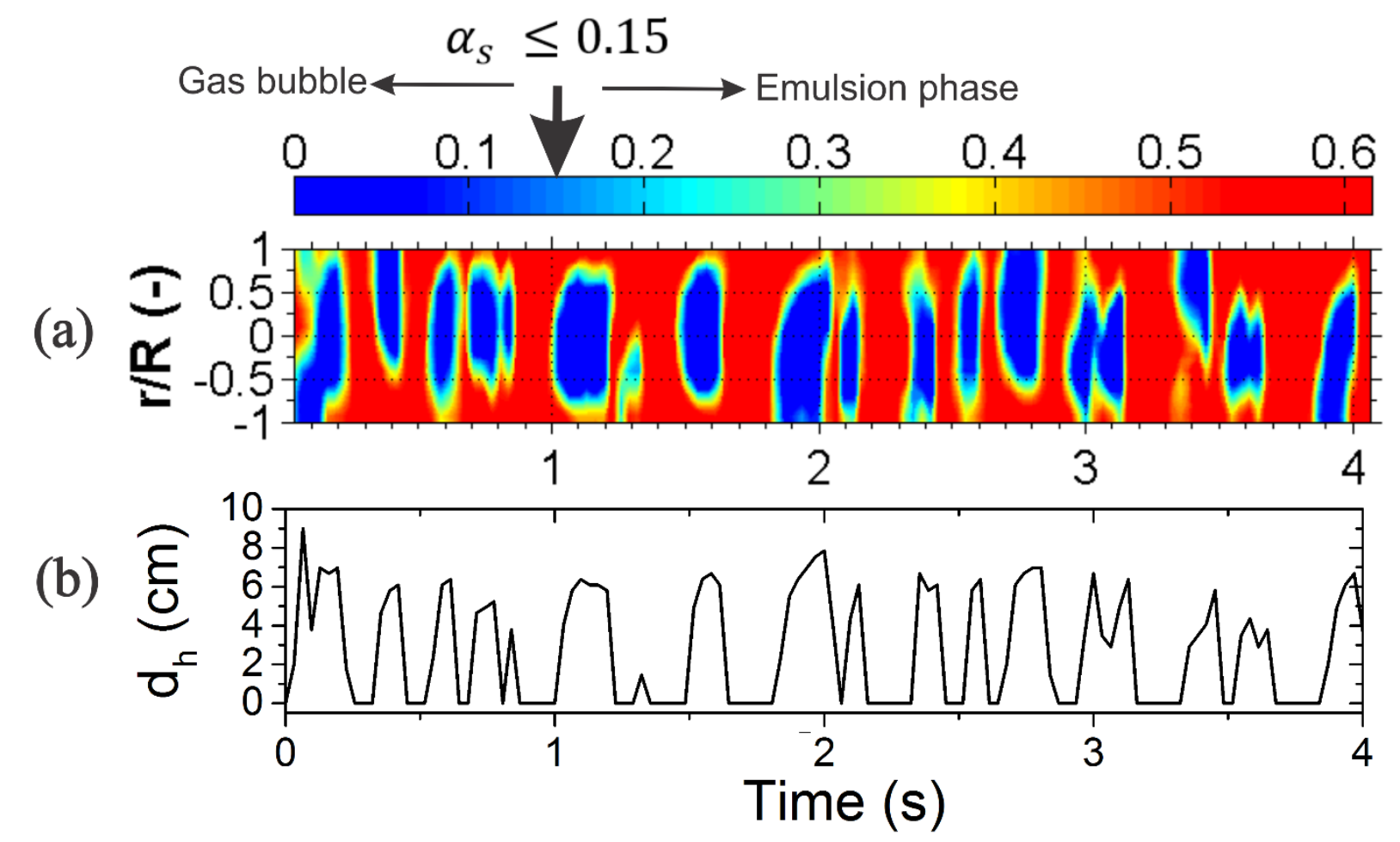

Figure S5. Time-evolution of (a) $\alpha_{s}$ distribution along the radial direction and (b) the corresponding time-evolution of bubble chord length (G96 particles, $\mathrm{z}=8.9 \mathrm{~cm}$, a threshold of $\alpha_{s}=0.15$ was used to discriminate the gas bubble and emulsion phases) ${ }^{4}$. 


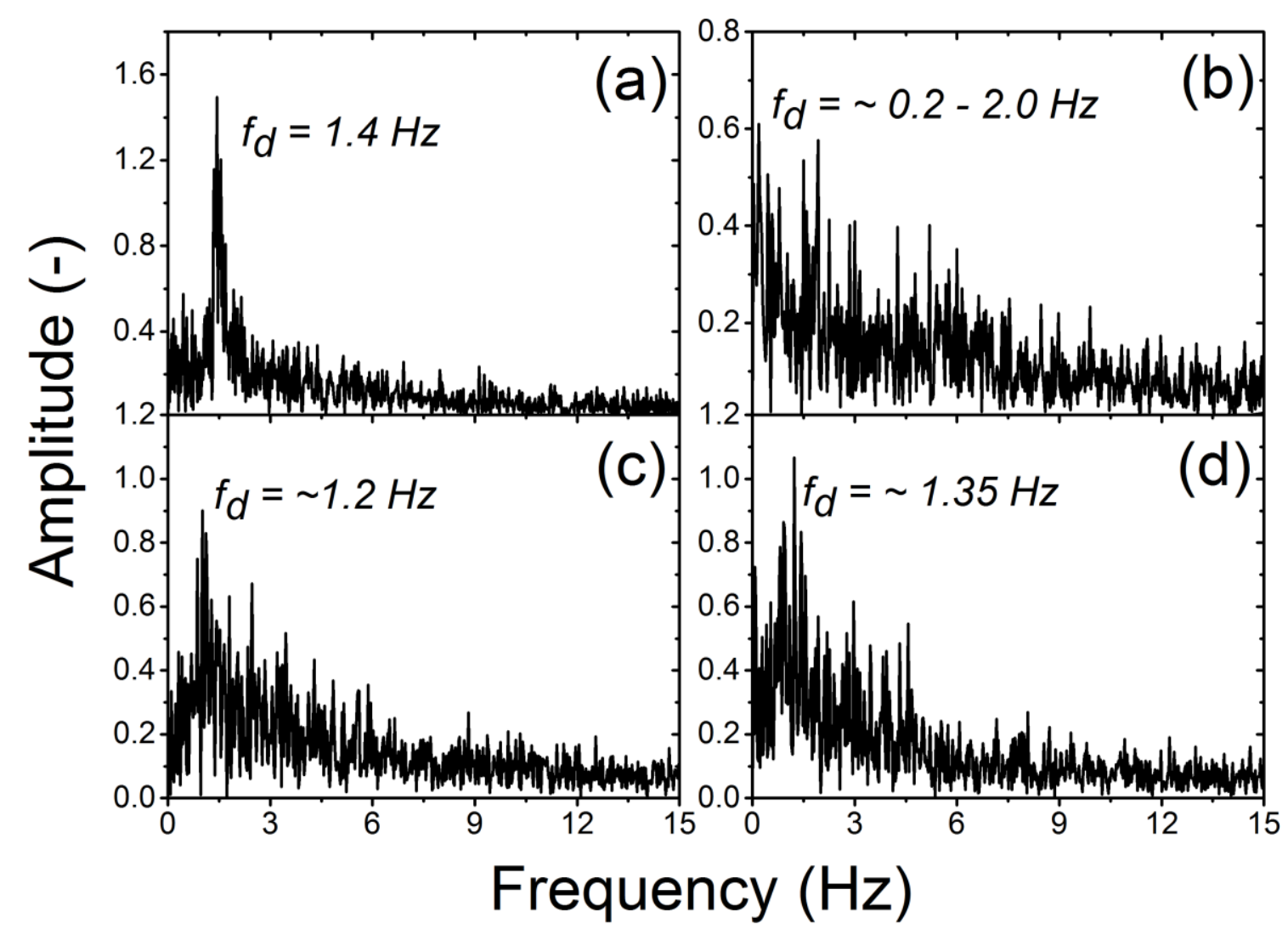

Figure S6. Power spectra of $\mathrm{d}_{\mathrm{h}}$ fluctuations (a) measured using the ECT, (b) predicted using KTGF- $\mu_{s, f r}$ model, (c) JJ- $\mu_{s, f r}$ with $\alpha_{s, \min }=0.5$ and (d) JJ- $\mu_{s, f r}$ with $\alpha_{s, \min }=0.55$ (G922, $\left.\mathrm{z}=24 \mathrm{~cm}, \mathrm{U}_{\mathrm{G}}=1.75 \mathrm{~m} / \mathrm{s}\right)$. 


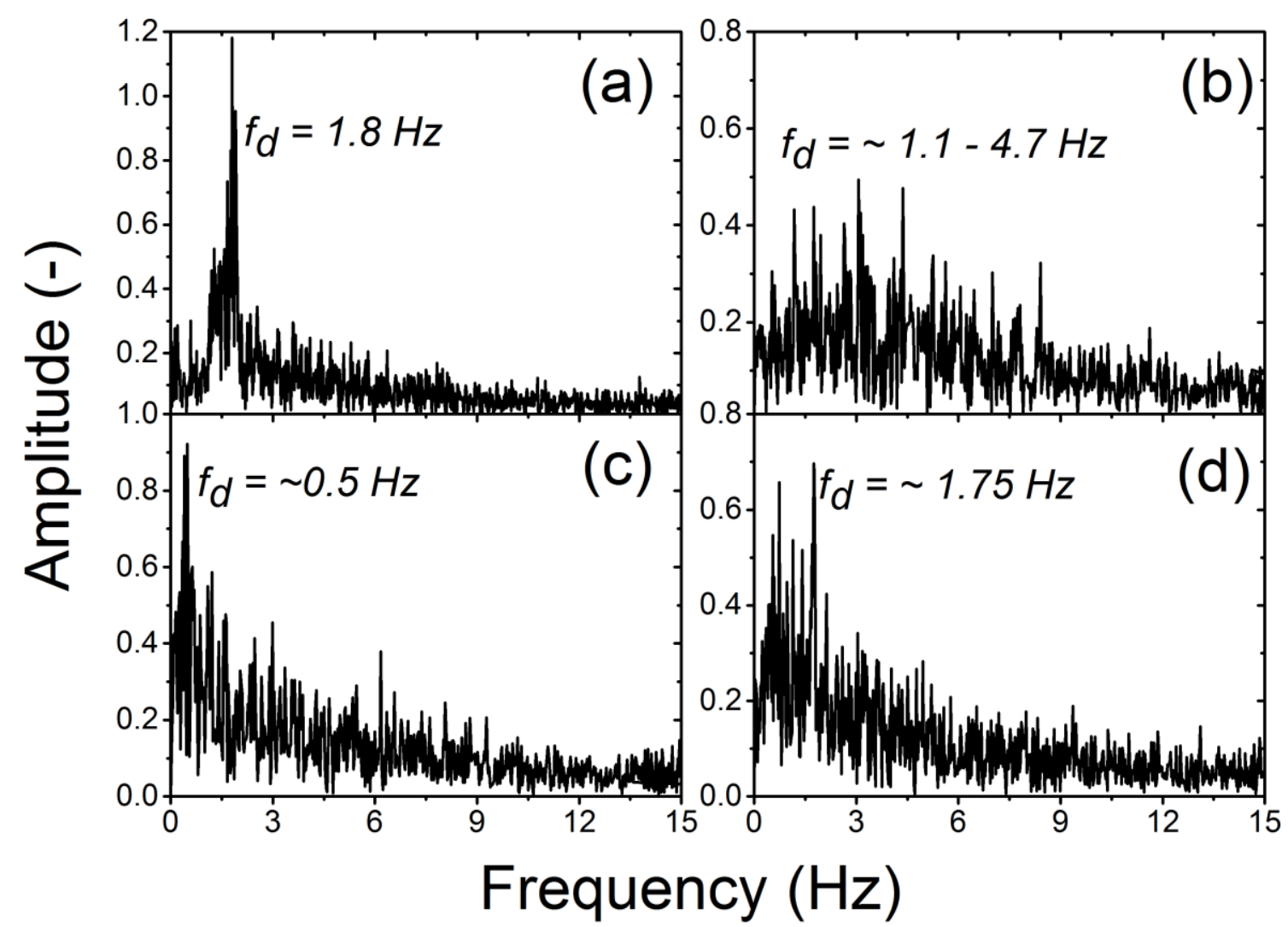

Figure S7. Power spectra of $d_{h}$ fluctuations (a) measured using the ECT, (b) predicted using KTGF- $\mu_{s, f r}$ model, (c) JJ- $\mu_{s, f r}$ with $\alpha_{s, \text { min }}=0.5$ and (d) JJ- $\mu_{s, f r}$ with $\alpha_{s, \text { min }}=0.55$ (G96, $\left.\mathrm{z}=24 \mathrm{~cm}, \mathrm{U}_{\mathrm{G}}=0.44 \mathrm{~m} / \mathrm{s}\right)$. 


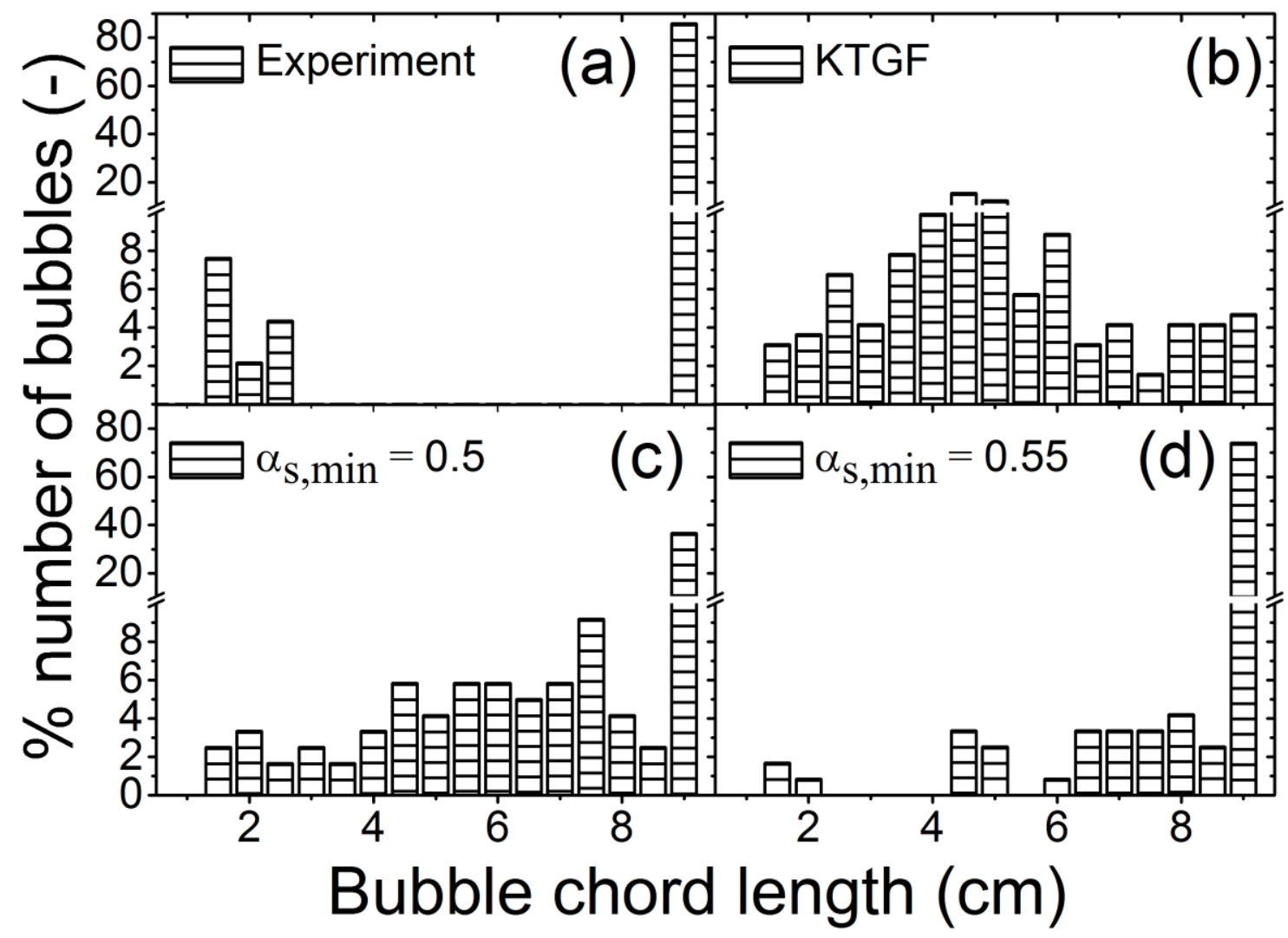

Figure S8. Bubble chord length distributions (a) measured using the ECT ${ }^{4}$, (b) predicted using KTGF- $\mu_{s, f r}$ model, (c) JJ- $\mu_{s, f r}$ with $\alpha_{s, \min }=0.5$ and (d) JJ- $\mu_{s, f r}$ with $\alpha_{s, \min }=0.55$ $\left(\mathrm{G} 922, \mathrm{z}=24 \mathrm{~cm}, \mathrm{U}_{\mathrm{G}}=1.75 \mathrm{~m} / \mathrm{s}\right)$. 


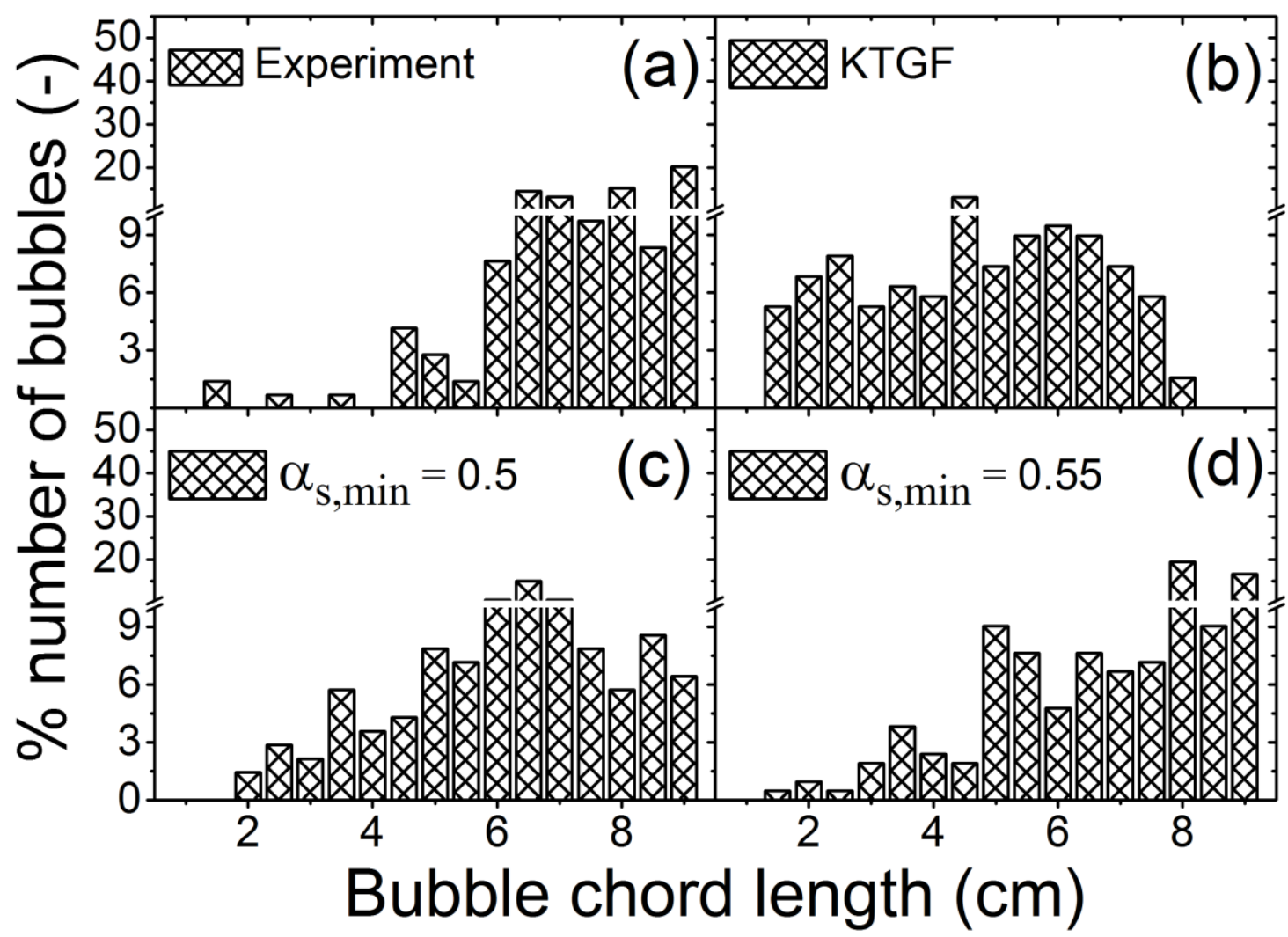

Figure S9. Bubble chord length distributions (a) measured using the ECT ${ }^{4}$, (b) predicted using KTGF- $\mu_{s, f r}$ model, (c) JJ- $\mu_{s, f r}$ with $\alpha_{s, \min }=0.5$ and (d) JJ- $\mu_{s, f r}$ with $\alpha_{s, \min }=0.55$ $\left(\mathrm{G} 96, \mathrm{z}=24 \mathrm{~cm}, \mathrm{U}_{\mathrm{G}}=0.44 \mathrm{~m} / \mathrm{s}\right)$. 


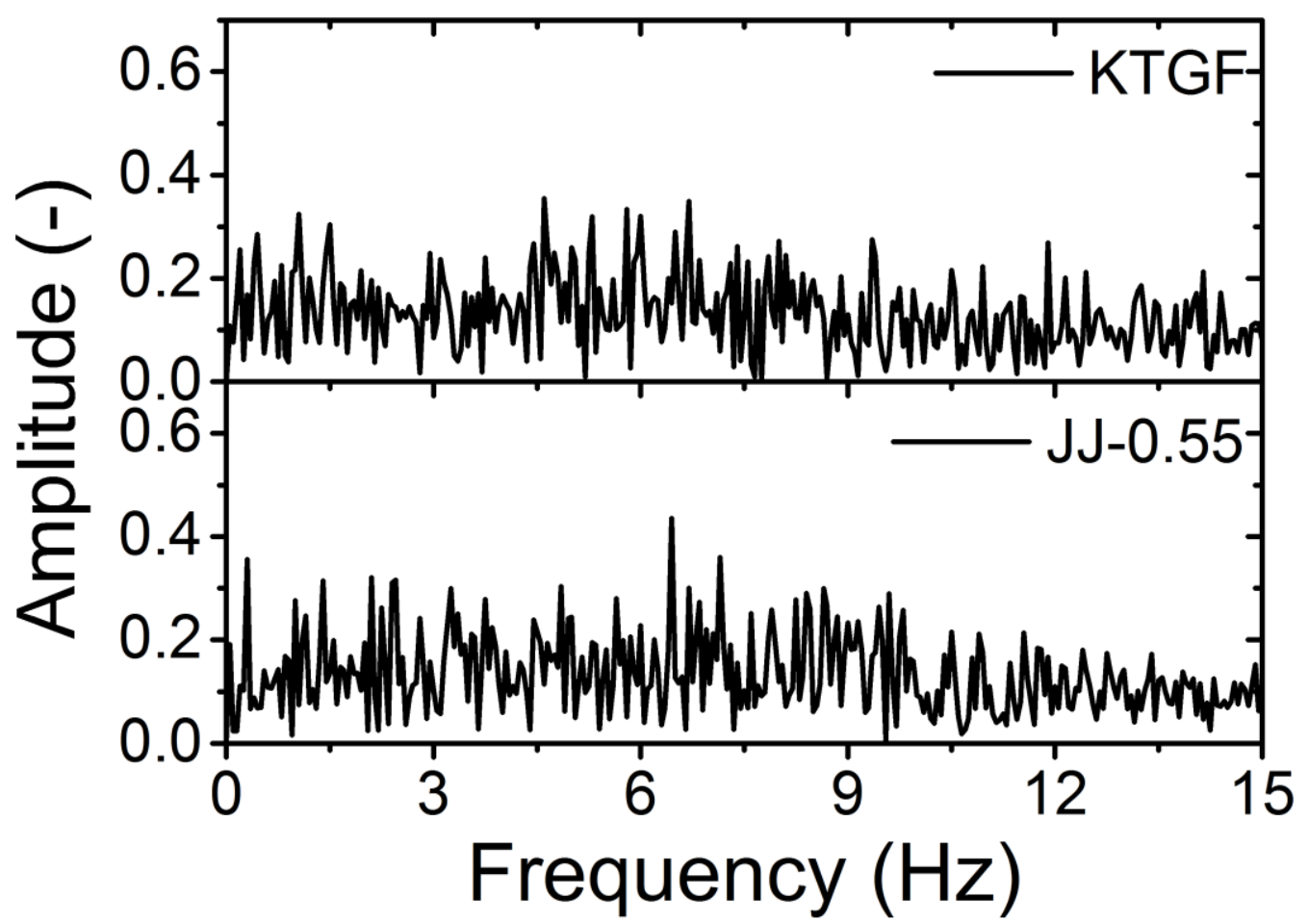

Figure S10. Power spectra of $\mathrm{d}_{\mathrm{h}}$ fluctuations predicted using KTGF- $\mu_{s, f r}$ and JJ- $\mu_{s, f r}$ with $\alpha_{s, \min }=0.55$ models for $\mathrm{A} 42$ and $\mathrm{U}_{\mathrm{G}}=0.22 \mathrm{~m} / \mathrm{s}(\mathrm{z}=24 \mathrm{~cm})$ 


\section{References:}

(1) Lun, C. K. K.; Savage, S. B.; Jeffrey, D. J.; Chepurniy, N. Kinetic Theories for Granular Flow: Inelastic Particle in Couette Flow and Slightly Inelastic Particle in a General Flow Field. J. Fluid Mech. 1984, 140, 223-256.

(2) Gidaspow, D. Multiphase Flow and Fluidization: Continuum and Kinetic Theory Descriptions; Academic Press, San Diego, 1994.

(3) Syamlal, M.; Rogers, W.; O'Brien, T. J. Mfix Documentation: Volume I, Theory Guide. Technical Report DOE/METC-9411004, NTIS/DE9400087; 1993.

(4) Singh, B. K.; Roy, S.; Buwa, V. V. Dynamics of Segregation and Fluidization of Binary Mixtures in a Cylindrical Fluidized Bed. AIChE J. 2019.

https://doi.org/10.1002/aic.16682. 